\title{
Brain Natriuretic Peptide Is a Powerful Predictor of Outcome in Stroke Patients with Atrial Fibrillation
}

\author{
Kenji Maruyama ${ }^{a}$ Shinichiro Uchiyama ${ }^{a, c}$ Tsuyoshi Shigab \\ Mutsumi Iijima $^{a}$ Kentaro Ishizuka ${ }^{a}$ Takao Hoshino $^{a}$ Kazuo Kitagawa ${ }^{a}$ \\ a Department of Neurology, Tokyo Women's Medical University School of Medicine, \\ Tokyo, Japan; ${ }^{\mathrm{b}}$ Department of Cardiology, Tokyo Women's Medical University School of \\ Medicine, Tokyo, Japan; ${ }^{\mathrm{C} C l i n i c a l ~ R e s e a r c h ~ C e n t e r, ~ I n t e r n a t i o n a l ~ U n i v e r s i t y ~ o f ~ H e a l t h ~ a n d ~}$ \\ Welfare, Center for Brain and Cerebral Vessels, Sanno Hospital and Sanno Medical Center, \\ Tokyo, Japan
}

\section{Keywords}

Brain natriuretic peptide $\cdot$ Nonvalvular atrial fibrillation - Stroke $\cdot$ Outcome $\cdot$ Modified Rankin Scale score $\cdot$ Systolic blood pressure $\cdot$ National Institutes of Health Stroke Scale

\begin{abstract}
Background: Since stroke patients with nonvalvular atrial fibrillation (NVAF) have poor outcomes in general, the prediction of outcomes following discharge is of utmost concern for these patients. We previously reported that brain natriuretic peptide (BNP) levels were significantly higher in NVAF patients with larger infarcts, higher modified Rankin Scale (mRS) score, and higher $\mathrm{CHADS}_{2}$ score. In the present study, we evaluated an array of variables, including BNP, in order to determine significant predictors for functional outcome in patients with NVAF after acute ischemic stroke (AIS). Methods: A total of 615 consecutive patients with AIS within $48 \mathrm{~h}$ of symptom onset, admitted to our hospital between April 2010 and October 2015, were retrospectively searched. Among these patients, we enrolled consecutive patients with NVAF. We evaluated the mRS score 3 months after onset of stroke and investigated associations between mRS score and the following clinical and echocardiographic variables. Categorical variables included male sex, current smoking, alcohol intake, hypertension, diabetes mellitus, dyslipidemia, coronary artery disease, peripheral artery disease, use of antiplatelet drugs, anticoagulants, or tissue plasminogen activator (tPA), and infarct size. Continuous variables included age, systolic blood pressure (SBP), diastolic blood pressure, hemoglobin, creatinine, D-dimer, brain natriuretic peptide (BNP), left atrial diameter, left ventricular ejection fraction (EF), and early mitral inflow velocity/diastolic mitral annular velocity
\end{abstract}


Maruyama et al.: Brain Natriuretic Peptide Is a Powerful Predictor of Outcome in Stroke Patients with Atrial Fibrillation

$\left(\mathrm{E} / \mathrm{e}^{\prime}\right)$. We also analyzed the association of prestroke $\mathrm{CHADS}_{2}, \mathrm{CHA}_{2} \mathrm{DS}_{2}-\mathrm{VASc}$, and $\mathrm{R}_{2} \mathrm{CHADS}_{2}$ scores, and National Institutes of Health Stroke Scale (NIHSS) score on admission with mRS score 3 months after the onset of stroke. Patients were classified into 2 groups according to mRS score: an mRS score $\leq 2$ was defined as good outcome, an mRS score $\geq 3$ was defined as poor outcome. To clarify the correlations between categorical or continuous variables and mRS score, uni- and multivariate logistic regression models using the stepwise variable selection method were applied. Results: Among 157 patients with NVAF after AIS, 63.7\% were male and the mean age was 75.9 years. In univariate regression analysis, poor outcome (mRS score 23) was associated with use of tPA, infarct size, age, SBP, BNP, EF, and NIHSS score. In multivariate regression analysis, BNP levels (odds ratio [OR] 6.40; $95 \%$ confidence interval [CI] $1.26-32.43 ; p=0.0235$ ) and NIHSS score (OR 2.87; 95\% CI 1.84-4.47; $p<0.001$ ) were significantly associated with poor outcome ( $m R S$ score $\geq 3$ ) after adjusting for use of tPA, infarct size, age, BNP, EF, and NIHSS score. Conclusions: Apart from NIHSS score, BNP was a very useful predictor for long-term outcomes of patients with NVAF after AIS.

(C) 2017 The Author(s)

Published by S. Karger AG, Basel

\section{Introduction}

Nonvalvular atrial fibrillation (NVAF) is an important risk factor for ischemic stroke especially in the elderly, and is a major cause of cardioembolic stroke (CES) [1]. Indeed, in the Framingham study, NVAF was shown to be an independent risk factor for stroke [2]. NVAFrelated stroke is associated with more disabling and fatal outcomes than stroke without NVAF [3]. Since NVAF-associated stroke leads to severe disability or death [4], there is an urgent need for a predictor of long-term outcome in NVAF patients after acute ischemic stroke (AIS). At present there are several predictors of functional outcome in NVAF patients after AIS, including the $\mathrm{CHADS}_{2}[5,6]$ and $\mathrm{CHA}_{2} \mathrm{DS}_{2}$-VASc scores [5, 7]. In addition, the $\mathrm{R}_{2} \mathrm{CHADS}_{2}$ score has been shown to be associated with not only severity at onset, but also functional outcome among NVAF patients after AIS [8]. A recent report indicated that plasma D-dimer levels on admission were correlated with both infarction volume and functional outcome [9]. Furthermore, elevated levels of serum BNP were reported to be associated with NVAF, CES, and poststroke mortality [10]. There were additional reports of the predictive value of BNP for outcome in patients with AIS $[11,12]$. We also reported that BNP levels were significantly higher in NVAF patients with larger infarcts, higher modified Rankin Scale (mRS) score, and higher $\mathrm{CHADS}_{2}$ score [12].

In the present study, we evaluated an array of variables, including BNP, in order to determine significant predictors for functional outcome in patients with NVAF after AIS.

\section{Methods}

Study Population and Procedure

This study was approved by the institutional ethics committee of our institute. A total of 615 consecutive patients with AIS within $48 \mathrm{~h}$ of symptom onset, admitted to the Department of Neurology at Tokyo Women's Medical University Hospital between April 2010 and October 2015, were retrospectively searched.

Subtypes of AIS were diagnosed according to the Trial of Org 10172 in Acute Stroke Treatment (TOAST) classification [13]. Among the 615 AIS patients searched, we extracted data from 168 NVAF patients with CES. Among them, we excluded patients with the following 
Maruyama et al.: Brain Natriuretic Peptide Is a Powerful Predictor of Outcome in Stroke Patients with Atrial Fibrillation

conditions: (1) dilated cardiomyopathy $(n=2),(2)$ hypertrophic cardiomyopathy $(n=2)$, (3) implantation of cardiac pacemakers $(n=1)$, and (4) embolism due to cardiac catheterization $(n=1)$. Finally, 157 were eligible for analysis. All patients were of East Asian ethnicity.

\section{Clinical Variables}

Categorical variables included sex, current smoking, alcohol drinking, hypertension (HT), diabetes mellitus (DM), dyslipidemia (DL), persistent atrial fibrillation (AF), coronary artery disease (CAD), peripheral artery disease (PAD), chronic kidney disease (CKD), and use of antiplatelet drugs, anticoagulants, and tissue plasminogen activator (tPA). HT was defined as blood pressure $\geq 140 / 90 \mathrm{~mm} \mathrm{Hg}$ on admission or use of antihypertensive agents. DM was defined as fasting blood glucose $\geq 126 \mathrm{mg} / \mathrm{dL}$ or random blood glucose $\geq 200 \mathrm{mg} / \mathrm{dL}$ and hemoglobin A1c $\geq 6.4 \%$ (National Glycohemoglobin Standardization Program) on admission or use of antidiabetic agents. DL was defined as serum low-density lipoprotein cholesterol $\geq 140 \mathrm{mg} / \mathrm{dL}$, high-density lipoprotein cholesterol $\leq 40 \mathrm{mg} / \mathrm{dL}$, or serum triglycerides $\geq 150$ $\mathrm{mg} / \mathrm{dL}$ on admission, or use of antihyperlipidemic agents such as statins or fibrates. AF was diagnosed by 24-h ambulatory ECG monitoring performed on admission. CAD was defined as history of any medical treatment for angina pectoris or myocardial infarction. PAD was defined as intermittent claudication and ankle-brachial index $<0.9$. CKD was defined as creatinine clearance $<60 \mathrm{~mL} / \mathrm{min}$ [14]. Antiplatelet drugs included aspirin, clopidogrel, and cilostazol; anticoagulants included warfarin and direct oral coagulants.

Continuous variables included age, systolic blood pressure (SBP), diastolic blood pressure (DBP), hemoglobin, serum creatinine, creatinine clearance, D-dimer, BNP, left atrial diameter (LAD), left ventricular ejection fraction (EF), and E/e'. Creatinine clearance was calculated by the Cockcroft-Gault formula [15]. The measurements of D-dimer, BNP, LAD, EF, and E/e' are described later.

We evaluated the National Institutes of Health Stroke Scale (NIHSS) score for each patient on admission [16]. Outcomes were evaluated using mRS score 3 months after stroke onset [17]. Patients were classified into 2 groups according to mRS score: $m R S$ score $\leq 2$ was defined as good outcome, mRS score $\geq 3$ was defined as poor outcome. Prestroke $\mathrm{CHADS}_{2}$ [18], $\mathrm{CHA}_{2} \mathrm{DS}_{2}$-VASc [19], and $\mathrm{R}_{2} \mathrm{CHADS}_{2}$ scores [20] were also calculated.

\section{Magnetic Resonance Imaging}

Magnetic resonance imaging of the brain was performed with 1.5-Tesla scanners. The areas of hyperintensity on diffusion-weighted images were used to measure infarct sizes. We classified the infarcts into 3 groups: small $(\mathrm{S} ; \leq 0.3$ to $1.5 \mathrm{~cm}$ ), large (L; more than one-third of the cerebral hemispheres), and medium (M; sizes between S and L). Sizes of S and M infarcts were $0.3-1.5 \mathrm{~cm}$ and $>1.5 \mathrm{~cm}$, respectively in the brain stem and the cerebellar hemisphere [12].

\section{Hemostatic Markers}

At the time of admission, venous blood samples were collected in order to measure D-dimer levels, which were quantified using the Nampia D-dimer kit (Sekisui Medical Co., Tokyo, Japan).

\section{Brain Natriuretic Peptide}

Whole blood samples were collected at the time of admission. Plasma BNP levels were measured using a chemiluminescence enzyme immunoassay (Fujirebio Inc., Tokyo, Japan). The assay used was a sandwich method that uses 2 monoclonal antibodies against human $\mathrm{BNP}$, one recognizing the carboxyl-terminal sequence and the other the ring structure of BNP [21]. 


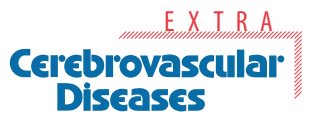

Table 1. Baseline characteristics of the 157 patients

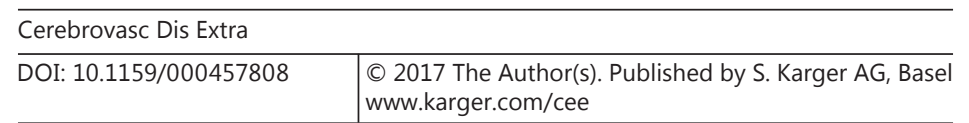

Maruyama et al.: Brain Natriuretic Peptide Is a Powerful Predictor of Outcome in Stroke Patients with Atrial Fibrillation

\begin{tabular}{lc}
\hline Characteristic & \\
\hline Male sex & $87(55.4 \%)$ \\
Current smoking & $19(12.1 \%)$ \\
Alcohol intake & $27(17.2 \%)$ \\
Hypertension & $110(70.1 \%)$ \\
Diabetes mellitus & $42(26.8 \%)$ \\
Dyslipidemia & $60(38.2 \%)$ \\
Persistent atrial fibrillation & $79(50.3 \%)$ \\
Coronary artery disease & $22(14.0 \%)$ \\
Peripheral artery disease & $4(2.5 \%)$ \\
Use of antiplatelet agents & $50(31.8 \%)$ \\
Use of warfarin & $37(23.6 \%)$ \\
Tissue plasminogen activator & $13(8.3 \%)$ \\
Infarction size & \\
$\quad$ Small & $37(23.6 \%)$ \\
$\quad$ Medium & $83(52.9 \%)$ \\
Large & $36(22.9 \%)$ \\
Age, years & $76.3 \pm 10.2$ \\
Systolic blood pressure, mm Hg & $145.6 \pm 29.9$ \\
Diastolic blood pressure, mm Hg & $82.9 \pm 18.3$ \\
Hemoglobin & $13.3 \pm 3.2$ \\
Serum creatinine & $1.4 \pm 1.9$ \\
D-dimer, $\mu$ g/mL & $4.3 \pm 16.2$ \\
Brain natriuretic peptide, pg/mL & $203.5[112.0-392.3]$ \\
Left atrial diameter, mm & $4.4 \pm 1.1$ \\
Ejection fraction, $\%$ & $49.3 \pm 7.1$ \\
E/e' & $14.4 \pm 7.9$ \\
Prestroke $\mathrm{CHADS}_{2}$ score & $2.2 \pm 1.2$ \\
Prestroke $\mathrm{CHA}_{2} \mathrm{DS}_{2}$-VASc score & $3.6 \pm 1.3$ \\
Prestroke $\mathrm{R}_{2} \mathrm{CHADS}_{2}$ score & $3.4 \pm 1.6$ \\
NIHSS score & $7.4 \pm 7.9$ \\
\hline
\end{tabular}

Values are represented as $\mathrm{n}(\%)$, mean \pm standard deviation, or median [interquartile range]. E, early mitral inflow velocity; e', diastolic mitral annular velocity; NIHSS, National Institutes of Health Stroke Scale.

\section{Echocardiography}

An experienced sonographer performed the echocardiographic studies with a SONOS 5500 (Philips Medical Systems, Amsterdam, The Netherlands) or an ARTIDA (Toshiba Medical Systems, Tokyo, Japan) ultrasound system equipped with a 2- to 4-MHz phased-array transducer during continuous ECG recording. Left ventricular systolic function was determined on the basis of the EF using the biplane Simpson's method from apical 2- and 4-chamber views [22]. LAD was measured using tomographic echocardiography. Tissue Doppler imaging was used to record mitral annulus velocities at the septal and lateral corners. Early diastolic (E') tissue Doppler velocities were measured, and the left atrial volume was assessed by the modified biplane area-length method and indexed to body surface area. Early mitral inflow velocity (E) was measured using the pulsed wave Doppler method. The tissue Dopplerderived diastolic mitral annular velocity (e') was measured from the septal corner of the mitral annulus in the apical 4-chamber view [23].

\section{Statistical Analyses}

Statistical analyses were performed using SAS version 9.4 (SAS Institute, Cary, NC, USA). Descriptive data were summarized as mean $\pm \mathrm{SD}$, median with interquartile range, and 
Maruyama et al.: Brain Natriuretic Peptide Is a Powerful Predictor of Outcome in Stroke Patients with Atrial Fibrillation

Table 2. Uni- and multivariate logistic regression models with stepwise variable selection methods predictors of poor outcomes

\begin{tabular}{|c|c|c|c|c|c|c|}
\hline & \multicolumn{3}{|c|}{ Univariate } & \multicolumn{3}{|c|}{ Multivariate } \\
\hline & OR & $95 \% \mathrm{CI}$ & $p$ value & OR & $95 \% \mathrm{CI}$ & $p$ value \\
\hline Male sex & 0.74 & $0.39-1.41$ & 0.356 & & & \\
\hline Current smoking & 1.17 & $0.44-3.09$ & 0.757 & & & \\
\hline Alcohol intake & 0.75 & $0.31-1.80$ & 0.658 & & & \\
\hline Hypertension & 1.03 & $0.51-2.09$ & 0.926 & & & \\
\hline Diabetes mellitus & 0.72 & $0.34-1.52$ & 0.392 & & & \\
\hline Dyslipidemia & 0.77 & $0.39-1.49$ & 0.436 & & & \\
\hline Persistent atrial fibrillation & 1.77 & $0.93-3.40$ & 0.084 & & & \\
\hline Coronary artery disease & 1.37 & $0.55-3.40$ & 0.494 & & & \\
\hline Peripheral artery disease & 4.91 & $0.50-48.34$ & 0.172 & & & \\
\hline Use of antiplatelet agents & 1.07 & $0.54-2.13$ & 0.840 & & & \\
\hline Use of warfarin & 0.95 & $0.44-2.02$ & 0.885 & & & \\
\hline Tissue plasminogen activator & 6.08 & $1.60-23.09$ & 0.008 & 1.24 & $0.08-18.58$ & 0.875 \\
\hline Infarct size & 6.27 & $3.21-12.23$ & $<0.001$ & 1.19 & $0.45-3.19$ & 0.724 \\
\hline Age & 1.04 & $1.01-1.08$ & 0.023 & 1.00 & $0.94-1.06$ & 0.993 \\
\hline SBP, per $10 \mathrm{~mm} \mathrm{Hg}$ increase & 1.11 & $0.99-1.25$ & 0.007 & & & \\
\hline DBP & 1.00 & $0.98-1.02$ & 0.860 & & & \\
\hline Hemoglobin & 0.98 & $0.88-1.10$ & 0.764 & & & \\
\hline Serum creatinine & 1.03 & $0.87-1.21$ & 0.748 & & & \\
\hline D-dimer & 1.00 & $0.98-1.02$ & 0.960 & & & \\
\hline BNP, per $100 \mathrm{pg} / \mathrm{mL}$ increase & 4.58 & $1.88-11.16$ & $<0.001$ & 6.34 & $1.25-32.18$ & 0.026 \\
\hline Left atrial diameter & 0.93 & $0.66-1.30$ & 0.662 & & & \\
\hline Ejection fraction & 0.93 & $0.88-0.98$ & 0.011 & 1.00 & $0.93-1.98$ & 0.996 \\
\hline$E / e^{\prime}$ & 1.01 & $0.96-1.06$ & 0.703 & & & \\
\hline Prestroke $\mathrm{CHADS}_{2}$ score & 1.10 & $0.84-1.45$ & 0.496 & & & \\
\hline Prestroke $\mathrm{CHA}_{2} \mathrm{DS}_{2}$-VASc score & 1.25 & $0.98-1.60$ & 0.075 & & & \\
\hline Prestroke $\mathrm{R}_{2} \mathrm{CHADS}_{2}$ score & 1.03 & $0.84-1.25$ & 0.804 & & & \\
\hline NIHSS score, per 4-point increase & 3.47 & $2.30-5.22$ & $<0.001$ & 2.92 & $1.80-4.75$ & $<0.001$ \\
\hline
\end{tabular}

BNP, brain natriuretic peptide; CI, confidence interval; DBP, diastolic blood pressure; E, early mitral inflow velocity; e', diastolic mitral annular velocity; NIHSS, National Institutes of Health Stroke Scale; OR, odds ratio; SBP, systolic blood pressure.

frequency (percentage). The $\chi^{2}$ test was used to compare variables across nominal categorical variables. To evaluate the impact of potential associated factors with respect to mRS score, both uni- and multivariate logistic regression models with stepwise method were applied. Two-tailed $p$ values $<0.05$ were considered statistically significant.

\section{Results}

The patients' baseline characteristics are shown in Table 1. Of 157 patients with NVAF after AIS, 87 (55.4\%) were male; the mean age was $76.3 \pm 10.2$ years. Seventy-nine patients (50.3\%) had persistent AF, the remainder had paroxysmal AF. tPA was administered to 13 patients (8.3\%). As for infarct size, 37 infarcts were small (23.6\%), 83 were medium (52.9\%), and 36 were large (22.9\%). The mean EF was $49.3 \pm 7.1 \%$.

Univariate logistic regression models showed that tPA (odds ratio [OR] 6.08; 95\% confidence interval [CI] 1.60-23.09; $p=0.008$ ), infarct size (OR 6.27; 95\% CI 3.21-12.23; $p<$ 0.001), age (OR 1.04; 95\% CI 1.01-1.08; $p=0.023$ ), SBP (OR 1.11; 95\% CI 0.99-1.25; $p=$ 0.007), BNP (OR 4.58; 95\% CI 1.88-11.16, per 100 pg/mL; $p<0.001$ ), EF (OR 0.93; 95\% CI 


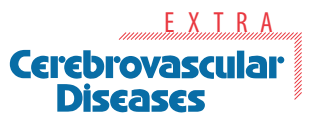

Fig. 1. Correlation between poor functional outcome (mRS score $\geq 3$ ) and BNP level. Higher BNP levels were associated with poor functional outcome (mRS score 23) 3 months after stroke. mRS, modified Rankin Scale; BNP, brain natriuretic peptide.

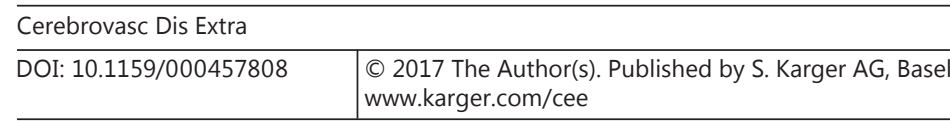

Maruyama et al.: Brain Natriuretic Peptide Is a Powerful Predictor of Outcome in Stroke Patients with Atrial Fibrillation

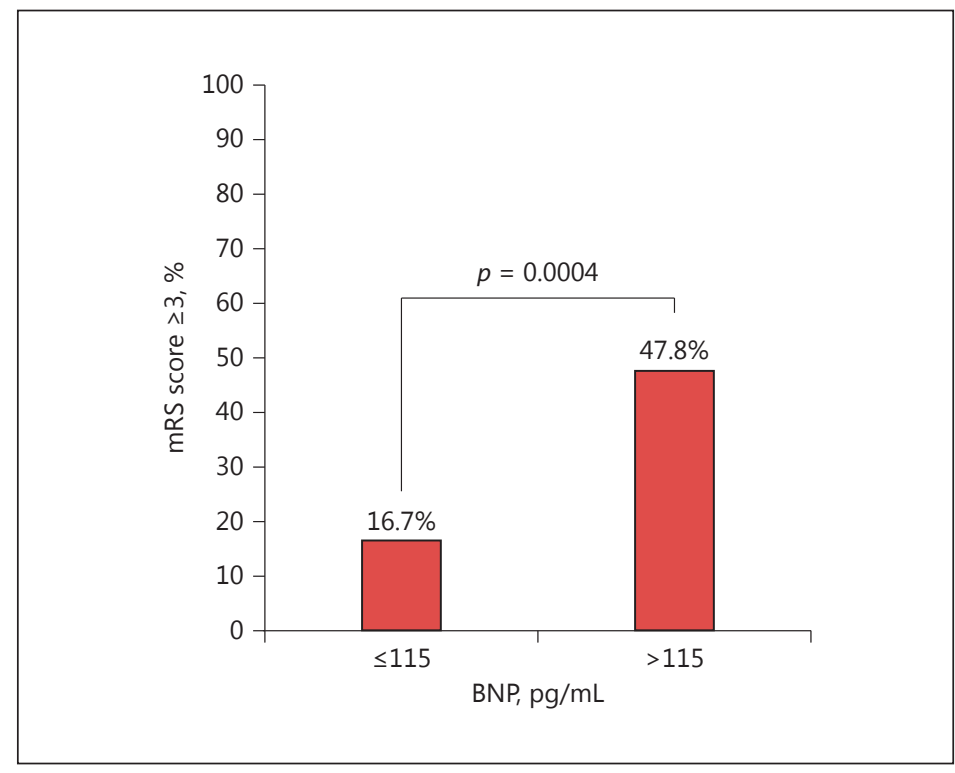

0.88-0.98; $p=0.011$ ), and NIHSS score (OR 3.47, per 4 points; 95\% CI 2.30-5.22; $p<0.001$ ) on admission were significantly correlated with mRS score at 3 months. On the other hand, there were no significant correlations of male sex, current smoking, alcohol intake, HT, DM, DL, persistent AF, CAD, PAD, antiplatelet agents, anticoagulants, SBP, DBP, hemoglobin, creatinine, creatinine clearance, $\mathrm{CKD}$, D-dimer, $\mathrm{LAD}, \mathrm{EF}, \mathrm{E} / \mathrm{e}^{\prime}$, prestroke $\mathrm{CHADS}_{2}$ score, prestroke $\mathrm{CHA}_{2} \mathrm{DS}_{2}$-VASc score, and prestroke $\mathrm{R}_{2} \mathrm{CHADS}_{2}$ score with mRS score (Table 2). Multivariate logistic regression models showed that only BNP (OR 6.34; 95\% CI 1.25-32.18, per $100 \mathrm{pg}$ / $\mathrm{mL} ; p=0.026$ ) and NIHSS score (OR 2.92; 95\% CI 1.8-4.75, per 4-point increase; $p<0.001$ ) were significantly correlated with mRS score at 3 months (Table 2). Our findings showed that higher BNP levels are associated with poor functional outcome (Fig. 1).

\section{Discussion}

Our study was conducted to find useful predictors for long-term outcome in NVAF patients with AIS. On hospital admission for AIS with NVAF, elevated serum BNP levels and NIHSS score independently predicted functional outcome of patients 3 months after stroke. Therefore, BNP as well as NIHSS score were the most useful predictors of functional outcome in NVAF patients after AIS.

We showed that tPA was associated with good outcome in uni- but not multivariate analysis. In our study, the number of patients treated with tPA was small, and tPA was not always effective because of the greater risk of intracerebral hemorrhage [24]. Infarct size was a significant predictor of outcome in uni- but not multivariate analysis. The outcome after stroke is associated with not only infarct size, but also infarct location [25]. However, we did not analyze the location of infarcts in this study. We previously reported that BNP levels increased as infarct size increased [12], but we did not perform multivariate analysis since the sample size was not big enough for this analysis in our previous study.

HT is an important risk factor [26] and predicts ischemic events in NVAF patients receiving anticoagulant therapy [27]. SBP was shown to be a significant prognostic factor in uni- but not multivariate analysis in this study. It was reported that a high initial SBP after 
Maruyama et al.: Brain Natriuretic Peptide Is a Powerful Predictor of Outcome in Stroke Patients with Atrial Fibrillation

acute stroke was correlated with poor outcome [28]. The statistical power might not have been enough to show a significant correlation after adjusting confounding factors in our study. Age and NIHSS score have been reported as the most powerful predictors of mortality and functional outcome after ischemic stroke $[29,30]$. However, age was significant in unibut not multivariate analysis in these studies, which was similar to our findings. There was a similar report that NIHSS score more strongly correlated with outcome than age [30]. In previous studies, NIHSS score on admission was shown to be associated with functional outcome 3 months after stroke [31,32]. Our results were consistent with the results of those studies. However, 1 report suggested that NIHSS score at admission does not always correspond to the outcome 3 months after stroke [33].

Apart from NIHSS score, plasma BNP was the only significant predictor of functional outcome in our NVAF patients after AIS. We demonstrated that BNP levels on admission were positively correlated with mRS score at 3 months in this study. Makikallio et al. [11] also found a relationship between increased BNP levels and mortality in the acute phase of cardioembolism, and ventricular EF and increased LAD were also associated with functional outcome and mortality. LAD was not significantly associated with mRS score in our study. Previously, we reported that serum BNP levels were associated with cardioembolism, infarct size, poor outcome, and risk of stroke in NVAF patients after AIS [12]. Other previous reports showed that BNP levels were associated with diffusion-weighted image lesion size and NIHSS scores on admission [34-36]. We demonstrated that BNP levels were positively correlated with mRS score in both uni- and multivariate analyses in this study. Consistently with our results, a recent report showed that plasma BNP levels were strongly associated with CES and functional outcome 6 months after ischemic stroke [37]. It was reported that in AF, BNP elevation is of atrial origin [38]. It was also reported that BNP level was significantly correlated with left atrial thrombi in AIS with AF [39]. Another study reported that BNP level was significantly correlated with left atrial appendage thrombi, and a stepwise increase in thrombi was significantly associated with a rise in BNP level [40]. We speculated that BNP increase is a reaction to infarction size or is due to cardiac disease. However, all subjects had preserved left ventricular systolic function in transthoracic echocardiography, and BNP was elevated by cardioembolism.

\section{Limitations}

Our study has several limitations. First, we retrospectively analyzed the clinical data in a cohort of a single center. Since the statistical power was weak in this study, a larger number of patients are required to provide appropriate conclusions. Second, our assessment of stroke volume was imprecise, evaluating only one slice of diffusion sequence on magnetic resonance imaging where the maximum diameter was detected. Third, timing of BNP measurement does not always correspond with the onset of stroke. Fourth, the risk factors were determined on admission from the patient's medical history. Therefore, prestroke states may not have definitely reflected risk factors.

In conclusions, plasma BNP levels were independently associated with functional outcomes 3 months after stroke onset. Plasma BNP is one of the most useful predictors for long-term functional outcomes of NVAF patients after AIS.

\section{Acknowledgments}

The authors thank Katsunori Shimada, PhD (Statz Institute, Inc., Tokyo, Japan) for assisting with statistical analysis. 


\begin{tabular}{l|l}
\hline \multicolumn{2}{l}{ Cerebrovasc Dis Extra } \\
\hline DOI: $10.1159 / 000457808$ & $\begin{array}{l}\text { (c) 2017 The Author(s). Published by S. Karger AG, Basel } \\
\text { www.karger.com/cee }\end{array}$ \\
\hline
\end{tabular}

Maruyama et al.: Brain Natriuretic Peptide Is a Powerful Predictor of Outcome in Stroke Patients with Atrial Fibrillation

\section{Disclosure Statement}

The authors have no conflicts of interest to disclose. This work received no grant support.

\section{References}

1 Yamanouchi H, Nagura H, Mizutani T, Matsushita S, Esaki Y: Embolic brain infarction in nonrheumatic atrial fibrillation: a clinicopathologic study in the elderly. Neurology 1997;48:1593-1597.

$>2$ Wolf PA, Abbott RD, Kannel WB: Atrial fibrillation as an independent risk factor for stroke: the Framingham Study. Stroke 1991;22:983-988.

-3 Lin HJ, Wolf PA, Kelly-Hayes M, Beiser AS, Kase CS, Benjamin EJ, D’Agostino RB: Stroke severity in atrial fibrillation. The Framingham Study. Stroke 1996;27:1760-1764.

4 Kimura K, Minematsu K, Yamaguchi T; Japan Multicenter Stroke Investigators' Collaboration (J-MUSIC): Atrial fibrillation as a predictive factor for severe stroke and early death in 15,831 patients with acute ischaemic stroke. J Neurol Neurosurg Psychiatry 2005;76:679-683.

5 Tu HT, Campbell BC, Meretoja A, Churilov L, Lees KR, Donnan GA, Davis SM: Pre-stroke CHADS2 and CHA2DS2VASc scores are useful in stratifying three-month outcomes in patients with and without atrial fibrillation. Cerebrovasc Dis 2013;36:273-280.

6 Hong HJ, Kim YD, Cha MJ, Kim J, Lee DH, Lee HS, Nam CM, Nam HS, Heo JH: Early neurological outcomes according to CHADS2 score in stroke patients with non-valvular atrial fibrillation. Eur J Neurol 2012;19:284290.

7 Giralt-Steinhauer E, Cuadrado-Godia E, Ois A, Jimenez-Conde J, Rodriguez-Campello A, Planellas L, JimenaGarcia S, Rubio MA, Roquer-Gonzalez J: CHA(2)DS(2)-VASc score and prognosis in ischemic strokes with atrial fibrillation. J Neurol 2012;259:745-751.

-8 Tanaka K, Yamada T, Torii T, Furuta K, Matsumoto S, Yoshimura T, Takase K, Wakata Y, Nakashima N, Kira J, Murai H: Pre-admission CHADS2, CHA2DS2-VASc, and R2CHADS2 scores on severity and functional outcome in acute ischemic stroke with atrial fibrillation. J Stroke Cerebrovasc Dis 2015;24:1629-1635.

-9 Matsumoto M, Sakaguchi M, Okazaki S, Furukado S, Tagaya M, Etani H, Shimazu T, Yoshimine T, Mochizuki H, Kitagawa K: Relationship between plasma (D)-dimer level and cerebral infarction volume in patients with nonvalvular atrial fibrillation. Cerebrovasc Dis 2013;35:64-72.

10 Montaner J, Garcia-Berrocoso T, Mendioroz M, Palacios M, Perea-Gainza M, Delgado P, Rosell A, Slevin M, Ribo M, Molina CA, Alvarez-Sabin J: Brain natriuretic peptide is associated with worsening and mortality in acute stroke patients but adds no prognostic value to clinical predictors of outcome. Cerebrovasc Dis 2012;34:240245.

11 Makikallio AM, Makikallio TH, Korpelainen JT, Vuolteenaho O, Tapanainen JM, Ylitalo K, Sotaniemi KA, Huikuri HV, Myllyla VV: Natriuretic peptides and mortality after stroke. Stroke 2005;36:1016-1020.

-12 Maruyama K, Shiga T, Iijima M, Moriya S, Mizuno S, Toi S, Arai K, Ashihara K, Abe K, Uchiyama S: Brain natriuretic peptide in acute ischemic stroke. J Stroke Cerebrovasc Dis 2014;23:967-972.

13 Adams HP Jr, Bendixen BH, Kappelle LJ, Biller J, Love BB, Gordon DL, Marsh EE 3rd: Classification of subtype of acute ischemic stroke. Definitions for use in a multicenter clinical trial. TOAST. Trial of Org 10172 in Acute Stroke Treatment. Stroke 1993;24:35-41.

14 National Kidney Foundation: K/DOQI clinical practice guidelines for chronic kidney disease: evaluation, classification, and stratification. Am J Kidney Dis 2002;39(2 suppl 1):S1-S266.

15 Cockcroft DW, Gault MH: Prediction of creatinine clearance from serum creatinine. Nephron 1976;16:31-41.

-16 Lyden PD, Lu M, Levine SR, Brott TG, Broderick J; NINDS rtPA Stroke Study Group: A modified National Institutes of Health Stroke Scale for use in stroke clinical trials: preliminary reliability and validity. Stroke 2001;32: 1310-1317.

17 van Swieten JC, Koudstaal PJ, Visser MC, Schouten HJ, van Gijn J: Interobserver agreement for the assessment of handicap in stroke patients. Stroke 1988;19:604-607.

18 Gage BF, Waterman AD, Shannon W, Boechler M, Rich MW, Radford MJ: Validation of clinical classification schemes for predicting stroke: results from the National Registry of Atrial Fibrillation. JAMA 2001;285:28642870.

19 Lip GY, Nieuwlaat R, Pisters R, Lane DA, Crijns HJ: Refining clinical risk stratification for predicting stroke and thromboembolism in atrial fibrillation using a novel risk factor-based approach: the Euro Heart Survey on Atrial Fibrillation. Chest 2010;137:263-272.

20 Piccini JP, Stevens SR, Chang Y, Singer DE, Lokhnygina Y, Go AS, Patel MR, Mahaffey KW, Halperin JL, Breithardt G, Hankey GJ, Hacke W, Becker RC, Nessel CC, Fox KA, Califf RM; ROCKET AF Steering Committee and Investigators: Renal dysfunction as a predictor of stroke and systemic embolism in patients with nonvalvular atrial fibrillation: validation of the R(2)CHADS(2) index in the ROCKET AF (Rivaroxaban Once-daily, oral, direct factor Xa inhibition Compared with vitamin $\mathrm{K}$ antagonism for prevention of stroke and Embolism Trial in Atrial Fibrillation) and ATRIA (AnTicoagulation and Risk factors In Atrial fibrillation) study cohorts. Circulation 2013;127:224-232. 
Maruyama et al.: Brain Natriuretic Peptide Is a Powerful Predictor of Outcome in Stroke Patients with Atrial Fibrillation

21 Ito Y, Namioka Y: Fundamental evaluation of two BNP assay reagents by chemiluminescent enzyme immunoassay using Lumipulse ${ }^{\circledR}$ F and Lumipulse Presto ${ }^{\circledR}$ II. Jpn J Med Pharm Sci 2010;64:931-939.

22 Helak JW, Plappert T, Muhammad A, Reichek N: Two dimensional echographic imaging of the left ventricle: comparison of mechanical and phased array systems in vitro. Am J Cardiol 1981;48:728-735.

-23 Currie PJ, Seward JB, Chan KL, Fyfe DA, Hagler DJ, Mair DD, Reeder GS, Nishimura RA, Tajik AJ: Continuous wave Doppler determination of right ventricular pressure: a simultaneous Doppler-catheterization study in 127 patients. J Am Coll Cardiol 1985;6:750-756.

24 Saposnik G, Gladstone D, Raptis R, Zhou L, Hart RG; Investigators of the Registry of the Canadian Stroke Network (RCSN) and the Stroke Outcomes Research Canada (SORCan) Working Group: Atrial fibrillation in ischemic stroke: predicting response to thrombolysis and clinical outcomes. Stroke 2013;44:99-104.

25 Menezes NM, Ay H, Wang Zhu M, Lopez CJ, Singhal AB, Karonen JO, Aronen HJ, Liu Y, Nuutinen J, Koroshetz WJ, Sorensen AG: The real estate factor: quantifying the impact of infarct location on stroke severity. Stroke 2007;38:194-197.

26 Lip GY, Boos CJ: Antithrombotic treatment in atrial fibrillation. Heart 2006;92:155-161.

-27 Poli D, Antonucci E, Cecchi E, Marcucci R, Liotta AA, Cellai AP, Lenti M, Gensini GF, Abbate R, Prisco D: Culprit factors for the failure of well-conducted warfarin therapy to prevent ischemic events in patients with atrial fibrillation: the role of homocysteine. Stroke 2005;36:2159-2163.

28 Soares I, Abecasis P, Ferro JM: Outcome of first-ever acute ischemic stroke in the elderly. Arch Gerontol Geriatr 2011;53:e81-e87.

29 Weimar C, Konig IR, Kraywinkel K, Ziegler A, Diener HC; German Stroke Study Collaboration: Age and National Institutes of Health Stroke Scale Score within 6 hours after onset are accurate predictors of outcome after cerebral ischemia: development and external validation of prognostic models. Stroke 2004;35:158-162.

-30 Konig IR, Ziegler A, Bluhmki E, Hacke W, Bath PM, Sacco RL, Diener HC, Weimar C; Virtual International Stroke Trials Archive (VISTA) Investigators: Predicting long-term outcome after acute ischemic stroke: a simple index works in patients from controlled clinical trials. Stroke 2008;39:1821-1826.

-31 Adams HP Jr, Davis PH, Leira EC, Chang KC, Bendixen BH, Clarke WR, Woolson RF, Hansen MD: Baseline NIH Stroke Scale score strongly predicts outcome after stroke: a report of the Trial of Org 10172 in Acute Stroke Treatment (TOAST). Neurology 1999;53:126-131.

-32 Sato S, Toyoda K, Uehara T, Toratani N, Yokota C, Moriwaki H, Naritomi H, Minematsu K: Baseline NIH Stroke Scale Score predicting outcome in anterior and posterior circulation strokes. Neurology 2008;70:2371-2377.

-33 Strambo D, Zambon AA, Roveri L, Giacalone G, Di Maggio G, Peruzzotti-Jametti L, La Gioia S, Galantucci S, Comi G, Sessa M: Defining minor symptoms in acute ischemic stroke. Cerebrovasc Dis 2015;39:209-215.

-34 Rivers CS, Wardlaw JM, Armitage PA, Bastin ME, Carpenter TK, Cvoro V, Hand PJ, Dennis MS: Do acute diffusionand perfusion-weighted MRI lesions identify final infarct volume in ischemic stroke? Stroke 2006;37:98-104.

-35 Thijs VN, Lansberg MG, Beaulieu C, Marks MP, Moseley ME, Albers GW: Is early ischemic lesion volume on diffusion-weighted imaging an independent predictor of stroke outcome? A multivariable analysis. Stroke 2000;31:2597-2602.

-36 Vanni S, Polidori G, Pepe G, Chiarlone M, Albani A, Pagnanelli A, Grifoni S: Use of biomarkers in triage of patients with suspected stroke. J Emerg Med 2011;40:499-505.

-37 Rost NS, Biffi A, Cloonan L, Chorba J, Kelly P, Greer D, Ellinor P, Furie KL: Brain natriuretic peptide predicts functional outcome in ischemic stroke. Stroke 2012;43:441-445.

38 Inoue S, Murakami Y, Sano K, Katoh H, Shimada T: Atrium as a source of brain natriuretic polypeptide in patients with atrial fibrillation. J Card Fail 2000;6:92-96.

-39 Okada Y, Shibazaki K, Kimura K, Matsumoto N, Iguchi Y, Aoki J, Kobayashi K, Sakai K: Brain natriuretic peptide is a marker associated with thrombus in stroke patients with atrial fibrillation. J Neurol Sci 2011;301:86-89.

-40 Doukky R, Gage H, Nagarajan V, Demopoulos A, Cena M, Garcia-Sayan E, Karam GJ, Kazlauskaite R: B-type natriuretic peptide predicts left atrial appendage thrombus in patients with nonvalvular atrial fibrillation. Echocardiography 2013;30:889-895. 